\title{
Genetic diversity of sugar beet under heat stress and deficit irrigation
}

\author{
Salah F. Abou-Elwafa ${ }^{1}$
}

${ }^{1}$ Agronomy Dept., Faculty of Agriculture, Assiut University, Assiut 71526, Egypt

${ }^{2}$ Soils and Water Dept., Faculty of Agriculture, Assiut University, Assiut 71526, Egypt

33793 N. 3600 E. USDA-ARS-NWISRL, Kimberly, ID 83301, USA

Correspondence

Salah F. Abou-Elwafa, Agronomy Dept., College of Agriculture, Assiut University, 71526 Assiut, Egypt.

Email:elwafa75@aun.edu.eg

Funding information

Beet Sugar Development Foundation, Grant/Award Number: Project No. 321

\author{
Abu El-Eyuoon A. Amin $^{2} \quad$ | Imad Eujayl ${ }^{3}$
}

\section{1 | INTRODUCTION}

The beet sugar industry in the tropical and subtropical regions, which are mostly developing countries (includ-

\footnotetext{
Abbreviations: Pol, sucrose content; QZ, quality index; RS, sugar recovery; RSY, recoverable sugar yield; RY, root yield; SL, sugar loss; SSI, stress susceptibility index; STI, stress tolerance index; SY, sugar yield; Ys, yield under deficit irrigation; YSI, yield stability index; Yp,

optimum-irrigated yield.
}

(C) 2020 The Authors. Agronomy Journal (c) 2020 American Society of Agronomy ing Egypt), is growing as an important component of sugar production (Abo-Elwafa, Abdel-Rahim, Abou-Salama, \& Teama, 2006; Balakrishnan \& Selvakumar, 2009). Recently, extensive efforts have been made to cultivate and adapt sugar beet in the tropical and subtropical countries in order to replace or supplement the sugar production from sugarcane. Sugar beet production dominates the industry outside these countries. One reason is that sugar beet has a lower irrigation requirement. The second reason is that sugar beet has a shorter growing season (5-6 mo). The third 
reason is that sugar beet could be a possible solution as a tolerant crop of soil alkalinity or for newly reclaimed soils, which are common in tropical and subtropical areas (AboElwafa et al., 2006; Mawusi, 2004; Nasr \& Abd El-Razek, 2008).

Cultivation of sugar beet in developing countries could be profitable for farmers in two ways: (a) by diversifying their incomes by enabling them to grow an additional cash crop, and (b) by supplying sugar factories with raw material in addition to the sugar cane that will extend the factories' supply for up to 10 mo of the year (Balakrishnan \& Selvakumar, 2009; Mandere, Persson, Anderberg, \& Pilesjo, 2010). Recently, tropical sugar beet varieties which are better adapted to cultivation in the tropical and subtropical regions have been launched by sugar beet breeding companies (Syngenta), and could be successfully grown under these conditions in India, Kenya, and Sudan with a reasonable sugar yield (Abdelgader, Eltahir, Abbas, \& Abdelrahim, 2013; Balakrishnan \& Selvakumar, 2009; Mandere et al., 2010; Mohammad, Ahmed, \& Marchelo-d'Ragga, 2015; Singh, Sidana, \& Kummar, 2018).

Deficit irrigation has adverse effects on agricultural production. Irrigation deficiency during the growing season is a critical issue that has a substantial effect on many plant growth- and development-related physiological processes. In the light of climate change and global warming, the development of drought tolerant cultivars is the most efficient and cost-effective strategy for fighting drought stress in low-input cropping systems (IPCC 2007; SimovaStoilova, Vassileva, \& Feller, 2016; Abou-Elwafa \& Shehzad, 2018).

Significant efforts have been made to minimize the effects of drought stress on sugar beet yield and quality. The occurrence of drought stress during early growth stages adversely affect sugar beet root growth and development. Furthermore, the occurrence of drought stress later in the growing season causes a reduction in leaf area and the number of leaves, and consequently decreases the photosynthetic efficiency. Besides, drought stress may increase the concentrations $\mathrm{Na}, \mathrm{K}$, and $\alpha$-amino $\mathrm{N}$, which negatively affect sugar extraction from roots (Putnik-Delić, Maksimović, Nagl, \& Lalić, 2018). The identification of morphological and/or physiological traits associated with drought tolerance and high yield potential is a challenge when selecting sugar beet genotypes with improved tolerance to deficit irrigation.

Genetic variation for drought tolerance is a crucial prerequisite for the development of stress-tolerant varieties. However, studies on the yield performance of commercial sugar beet variations under drought conditions have not revealed any significant genotypic variations, indicating the narrow genetic base of commercial varieties (Moosavi,

\section{Core Ideas}

- Evaluation of 18 sugar beet breeding lines identified six high-yielding lines under high temperature conditions.

- Stress tolerance index (STI) revealed significant positive correlation with root and sugar yields.

- STI is a reliable stress index to select high yielding lines under optimum and stressed irrigation.

- Two breeding lines adapted to deficit irrigation and high temperature were identified.

- These two lines are suitable for utilization in sugar beet breeding programs for such stresses.

Ramazani, Hemayati, \& Gholizade, 2017; Sen \& Alikamanoglu, 2012). Furthermore, selecting the appropriate plant idiotype for specific agroecological conditions is a great challenge in sugar beet breeding programs. However, introgression of exotic wild germplasm into sugar beet breeding lines requires additional time and cost to get rid of weedy characteristics while maintaining desired agronomic traits. Therefore, conducting such experiments are of immense importance in determining research direction and in designing strategies for breeding programs (Moosavi et al., 2017; Ober \& Luterbacher, 2002; Ober et al., 2005; Sen \& Alikamanoglu, 2012; Shaw, Thomas, \& Cooke, 2002).

The current study aims to (a) evaluate sugar beet genotypes for heat stress tolerance under deficit irrigation conditions, (b) identification and selection of heat- and drought-tolerant genotypes to initiate a national program for sugar beet germplasm enhancement in Egypt, and (c) introduce the gated-pipe system as a powerful irrigation system in sugar beet cultivation in Egypt.

\section{2 | MATERIALS AND METHODS}

\section{1 | Plant materials}

A set of 17 sugar beet breeding lines designated USC9446-64, USC944-6-68, USC944-6-77, USC944-19-12, USKEMS19-15, USKEMS-19-17, USKEMS-19-19, USK39-1-61, USK391-20, USKEMS-08, USKEMS-09, USKEMS-11, USKEMS-1, USKEMS-12, USC944-6-63, USKEMS-43, USC944-19-08, produced at the USDA-ARS-NWISRL, Kimberly Sugar beet Research Project, ID (Supplemental Table 1) in addition to the commercial sugar beet cultivar Kawimera were evaluated for yield and quality under high temperature and deficit irrigation conditions. 


\section{2 | Field experiments and deficit irrigation treatments}

All field experiments were carried out at Assiut University Experimental Farm $\left(27^{\circ} 03^{\prime} \mathrm{N}, 31^{\circ} 01^{\prime} 70 \mathrm{~m}\right.$ asl $)$. In the first growing season (2016-2017), plants were evaluated under the high temperature conditions prevailing in southern Egypt. Plants were sown on 15 Sept. 2016 and harvested on 2-3 Apr. 2017. Seeds from each of the 18 genotypes were hand sown at $15-$ to $20-\mathrm{cm}$ spaces in a $10.50-\mathrm{m}^{2}$ plot consisting of five rows of 3-m length, with a distance of $70 \mathrm{~cm}$ between rows.

In the second growing season (2017-2018), the best six performing genotypes (USC944-6-68, USKEMS-08, USKEMS-09, USKEMS-12, USKEMS-19-17, USKEMS-1919), in addition to breeding line USKPS25 and the commercial cultivar Kawimera, were evaluated for yield and quality under deficit irrigation and high temperature conditions. Planting and experimental units were the same as in the previous growing season. Plants were sown on 17 Sept. 2018 and harvested on 1 Apr. 2018.

In the third growing season (2018-2019), the same eight genotypes of the 2017-2018 season were re-evaluated for the same yield and quality traits under deficit irrigation conditions using gated-pipe irrigation system as an improved system for irrigation. Each experimental unit consists of six 70-cm spaced rows of $2.5 \mathrm{~m}$ in length with an area of $10.50 \mathrm{~m}^{2}$. Sowing was performed at $10-\mathrm{cm}$ spaces between plants.

Irrigation was applied based on measuring the soil field capacity using the undisturbed method essentially described by Ali (2010). Optimum irrigation was applied when the soil moisture reached $40 \%$ of the field capacity, meanwhile the deficit irrigation experiments were irrigated when the soil moisture reached about $26 \%$ of the soil field capacity ( $65 \%$ of the optimum-irrigated experiments).

\section{3 | Phenotypic evaluation}

At harvest, root yield was determined using roots from the three guarded rows of each plot, and a sample of $\sim 5 \mathrm{~kg}$ of roots were collected for quality analysis at the Egyptian Sugar and Integrated Industries Company (ESIIC) in Abu Qurqas sugar factory lab. Pol\% (sucrose content), $\mathrm{Na} \%, \mathrm{~K} \%$, $\alpha$-amino $\mathrm{N}$, and quality index (QZ) were measured. Theoretical sugar recovery \% (RS\%) and sugar loss \% (SL\%) were calculated according to Reinefield, Merich, Baumgarten, Winner, and Besis (1974) as follow:

$$
\begin{aligned}
\text { Sugar recovery } \%= & \text { Pol }-0.29-0.343(\mathrm{~K}+\mathrm{Na}) \\
& -0.094(\alpha-\text { amino } \mathrm{N})
\end{aligned}
$$

Sugar loss $\%=0.343(\mathrm{~K}+\mathrm{Na})+0.094(\alpha-$ amino $\mathrm{N})+0.29$

Recoverable sugar yield (RSY) and sugar losses yield (SLY) in tons per acre were calculated.

Stress tolerance indices were calculated using the following formulas according to Fernandez (1992), Hossain et al. (1990), Fischer \& Maurer (1978), and Bouslama \& Schapaugh (1984):

$$
\begin{gathered}
\text { Stress tolerance index }(\mathrm{STI})=\frac{y_{p}+y_{s}}{\bar{y}_{p}^{2}} \\
\text { Stress tolerance }(\mathrm{TOL})=y_{p}-y_{s} \\
\text { Stress susceptibility index (SSI) }=\frac{1-\left(y_{p} / y_{s}\right)}{1-\left(\bar{y}_{s} / \bar{y}_{p}\right)} \\
\text { Yield stability index (YSI) }=\frac{y_{s}}{y_{p}}
\end{gathered}
$$

where $y_{p}$ is average of a genotype under optimum irrigation conditions, $y_{s}$ is mean of the same genotype under deficit irrigation conditions, and $\bar{y}_{s}$ and $\bar{y}_{p}$ are the average yields of all genotypes in deficit irrigation and optimum-irrigated environments, respectively.

\section{4 | Experimental design and statistical analysis}

In the first growing season, the experiment was laid out in a six-replicates randomized complete block design (RCBD). In the second and third growing seasons, a four-replicates RCBD arranged in a split-plot design was implemented in designing the experiments. Irrigation treatments were assigned to the main plots and sugar beet genotypes to the sub-plots. The Proc Mixed of SAS package version 9.2 was implemented to perform analysis of variance (ANOVA), Fisher's least significant difference (LSD), linear regression and Pearson correlation coefficients $(R)$ among measured traits and stress tolerance indices.

\section{3 | RESULTS}

\section{1 | Phenotypic evaluation}

All measured and calculated phenotypic traits showed significant differences among evaluated genotypes (Supplemental Table 1). Analysis of variance also exhibited highly significant differences between optimum irrigated and deficit irrigation treatments in all studied phenotypic traits, except $\mathrm{Na}$ and $\mathrm{K}$ concentrations, 
under both irrigation systems (Supplemental Table 2). Except for impurity traits, the ANOVA revealed highly significant genotype $\times$ environment interaction. Root and recoverable sugar yields, impurities concentrations, and sugar losses yield were significantly decreased in response to deficit irrigation (Tables 1, 2; Figure 1). Meanwhile, Pol\%, quality index, and theoretical sugar recovery percentage (RS\%) were increased under deficit irrigation conditions compared to the optimum-irrigated treatment (Tables 1, 2).

Pearson correlation coefficients $(R)$ among the studied traits under both the optimum- and the deficit-irrigation conditions were calculated (Table 3). Root yield exhibited highly significant positive correlations with recoverable sugar yield (RSY) and sugar losses yield (SLY). Sucrose content showed highly significant positive correlations with theoretical sugar recovery $\%$ and the quality index. As expected, highly significant positive correlations between impurity traits ( $\mathrm{Na} \%, \mathrm{~K} \%$, and $\alpha$-amino $\mathrm{N}$ ) and sugar loss (SL) were observed. Meanwhile, the correlations between impurity traits and SL\% with quality index were highly significantly negative. Results showed that correlation between theoretical sugar recovery \% (RS) and quality index is highly significantly positive (Supplemental Table 2).

\section{2 | Effect of deficit irrigation and genotypes on root yield}

Root yield exhibited highly significant differences between genotypes, environments, and the interaction as well (Table 2). In general, root yield in the third growing season was significantly higher than the first growing season under either optimum- or deficit-irrigation conditions. Root yield was significantly reduced in response to deficit irrigation by 24.54 and $6.73 \%$ in the second and third growing seasons, respectively (Tables 1, 2). Although, the commercial cultivar Kawimera produced the highest root yield under either optimum- or deficit-irrigation conditions in both growing seasons. The breeding line USKPS25 significantly surpassed the other five breeding lines in the second season under both irrigation levels and produced a root yield that did not differ significantly from Kawimera (Tables 1, 2).

\section{3 | Effect of deficit irrigation and genotypes on quality parameters (Pol\% and QZ)}

Sucrose content and QZ were highly significantly affected by genotypes, irrigation levels, and their interaction. Sucrose content was higher in the third growing season under optimum- and deficit-irrigation conditions. Sucrose content and QZ were significantly increased in response to deficit irrigation by 0.25 and $1.5 \%$, and 0.44 and $1.5 \%$ in the second and third growing seasons, respectively (Table 1). In the second season, genotypes USKPS25 and Kawimera produced the highest Pol\% and QZ under optimum-irrigation conditions, whereas the superiority in Pol\% and QZ was scored for USKPS25 under deficit-irrigation conditions. In the third growing season, both USKPS25 and Kawimera yielded the highest values of Pol\% and QZ under either optimum- or deficit-irrigation conditions (Table 2).

\section{4 $\quad$ Effect of deficit irrigation and genotypes on impurities $(\mathrm{Na} \%, \mathrm{~K} \%$, and $\alpha$-amino N)}

Deficit irrigation led to a significant reduction in the roots content of $\alpha$-amino- $N$ in both growing seasons (Supplemental Table 2). Sodium content, $\mathrm{K} \%$, and $\alpha$-amino $\mathrm{N}$ differed significantly among genotypes. Genotypes USKPS25 and Kawimera produced the lowest values of $\mathrm{Na} \%, \mathrm{~K} \%$, and $\alpha$-amino $\mathrm{N}$ in the second growing season under both optimum- and deficit-irrigation conditions (Table 1). However, in the third growing season, only the commercial cultivar Kawimera produced the lowest values of impurity traits under both optimum- and deficit-irrigation conditions (Table 2).

\section{5 | Effect of deficit irrigation and genotypes on sugar recovery}

Sugar recovery (RS\%) was significantly increased in response to deficit irrigation under both growing seasons as tested by ANOVA, however, RS\% did not differ significantly between growing seasons (Supplemental Table 2). The highest values of RS\% were produced by the genotypes USKPS25 and Kawimera (17.80 and 17.87\%, and 18.65 and $17.74 \%$ under both optimum-irrigated and deficit irrigation conditions, in the second growing season, respectively, and 16.55 and $16.44 \%$, and 17.93 and $18.24 \%$ under optimum-irrigated and deficit irrigation conditions, in the third growing season, respectively (Tables 1, 2).

\section{6 | Effect of deficit irrigation and genotypes on recoverable sugar yield}

Recoverable sugar yield (RSY) exhibited highly significant differences between genotypes, environments, and the interaction as well (Supplemental Table 2). Deficit irrigation treatment has significantly reduced RSY in both 
눙 $\begin{array}{llllllllllllll}+1 & +1 & +1 & +1 & +1 & +1 & +1 & +1 & +1 & +1 & +1 & +1 & +1 & +1 \\ +1 & +1\end{array}$

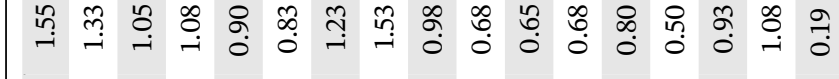

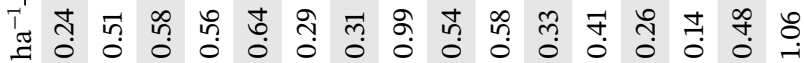

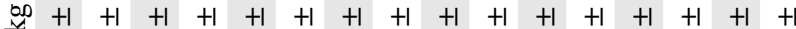
\&

苞

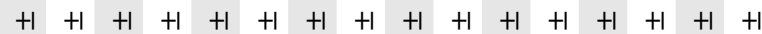

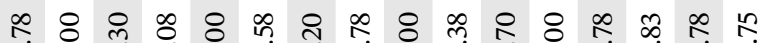

रं मिं

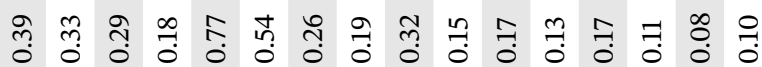

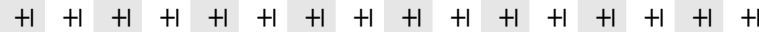
光 $\stackrel{9}{i}$ 茯

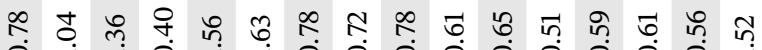

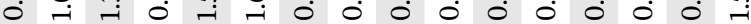
$\begin{array}{lllllllllllllllllll} & +1 & +1 & +1 & +1 & +1 & +1 & +1 & +1 & +1 & +1 & +1 & +1 & +1 & +1 & +1 & +1\end{array}$

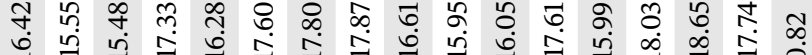

นี

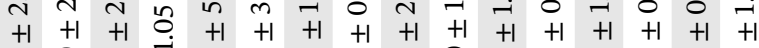

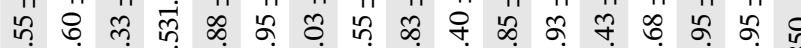

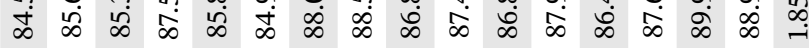

Э $\begin{array}{lllllllllllllll}+1 & +1 & +1 & +1 & +1 & +1 & +1 & +1 & +1 & +1 & +1 & +1 & +1 & +1 & +1\end{array}$

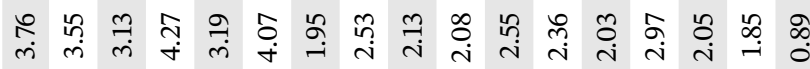

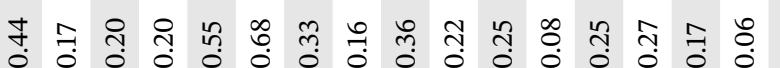

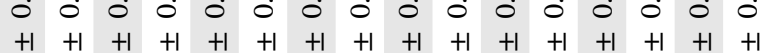
ஷ

th

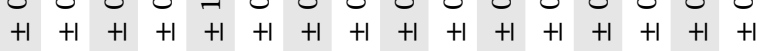

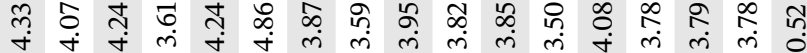

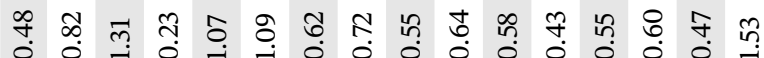

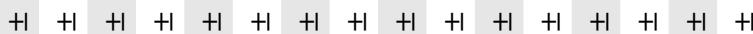

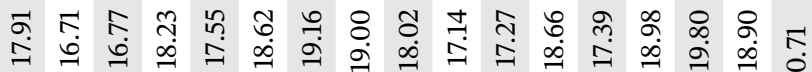




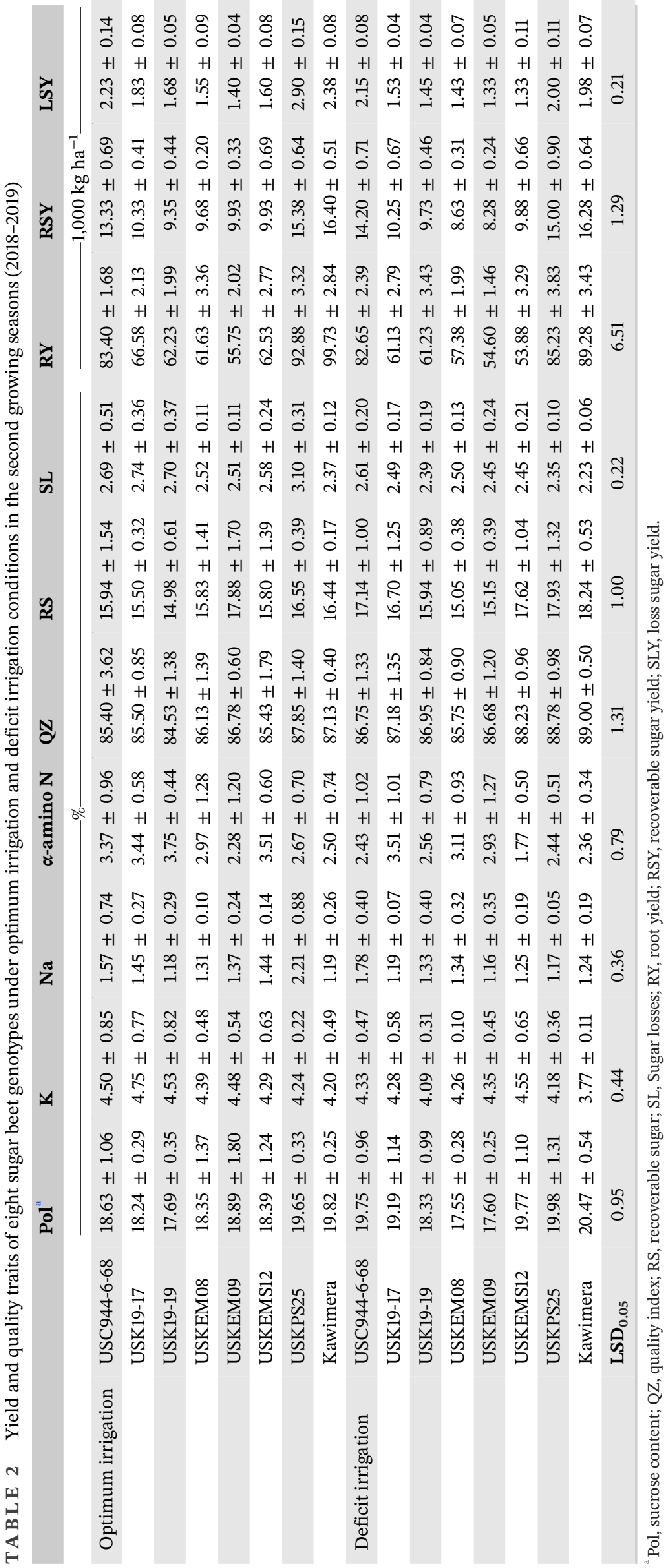



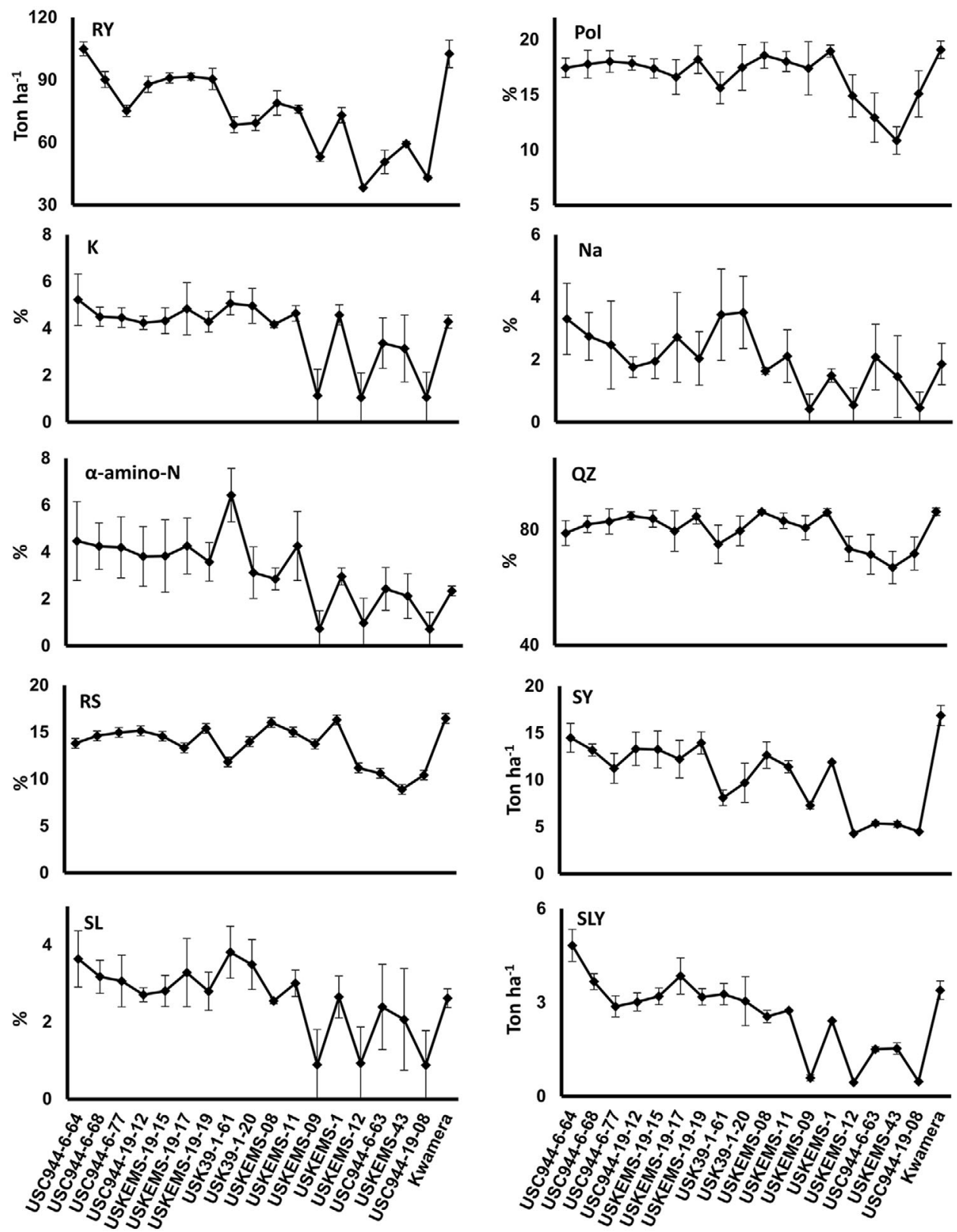

F I G U R E 1 Evaluation of 18 sugar beet breeding lines and a commercial cultivar (Kawimera) for yield performance and quality traits under high temperatures. RY, root yield; Pol, sucrose content; QZ, quality index; RS, recoverable sugar; SL, sugar losses; RSY, recoverable sugar yield; SLY, loss sugar yield

growing seasons. Genotypes USKPS25 and Kawimera produced the highest RSY in both growing seasons under both optimum- and deficit-irrigation conditions (Tables 1,2).

\section{7 | Effect of deficit irrigation and genotypes on sugar loss}

Sugar loss yield were significantly reduced under deficit irrigation conditions in both growing seasons (Supplemental Table 2). Genotypes USKPS25 and Kawimera produced the lowest SL\% in both growing seasons under both optimum- and deficit-irrigation conditions, however, both genotypes produced the highest sugar loss yields because of their high root yields (Tables 1, 2). Sugar loss (\%) and sugar loss yield differed significantly between growing seasons (Supplemental Table 2).

\section{8 | Root and sugar yields correlation to stress tolerance indices}

Stress tolerance indices were calculated based on root and sugar yields of genotypes over the two growing seasons (Table 4). Results showed that the greater the stress 
TA B L E 3 Pearson correlation coefficient (R) calculated between studied traits under deficit irrigation conditions over the two growing seasons 2017-2018 and 2018-2019

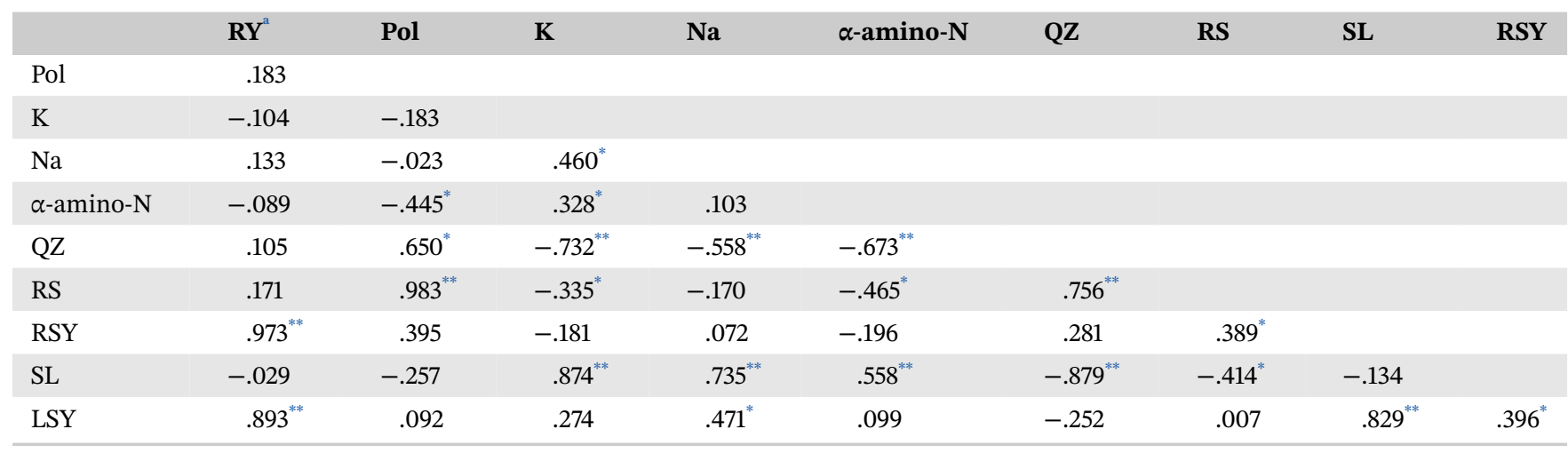

*Significant at the .05 probability level;

${ }^{* *}$ Significant at the .01 probability level.

${ }^{a}$ RY, root yield; Pol, sucrose content; QZ, quality index; RS, recoverable sugar; SL, Sugar losses; RY, root yield; RSY, recoverable sugar yield; SLY, loss sugar yield.

TA B L E 4 Drought stress indices for root and recoverable sugar yields of eight sugar beet genotypes over the two growing seasons

\begin{tabular}{|c|c|c|c|c|c|c|c|c|c|c|c|c|}
\hline & \multicolumn{6}{|c|}{ Root yield stress indices } & \multicolumn{6}{|c|}{ Recoverable sugar yield stress indices } \\
\hline & $\overline{\mathbf{R Y p}}{ }^{\mathrm{a}}$ & RYs & STI & TOL & SSI & $\overline{\text { YSI }}$ & $\overline{\text { SYp }}$ & SYs & STI & TOL & SSI & $\overline{\text { YSI }}$ \\
\hline USC944-6-68 & 30.84 & 27.53 & 1.11 & 3.31 & 1.11 & 0.88 & 30.84 & 27.53 & 1.11 & 3.31 & 1.11 & 0.88 \\
\hline USK19-19 & 23.51 & 20.18 & 0.62 & 3.33 & 1.48 & 0.85 & 23.51 & 20.18 & 0.62 & 3.33 & 1.48 & 0.85 \\
\hline USKEM08 & 25.14 & 20.48 & 0.67 & 4.66 & 2.38 & 0.82 & 25.14 & 20.48 & 0.67 & 4.66 & 2.38 & 0.82 \\
\hline USKPS25 & 33.01 & 29.20 & 1.26 & 3.81 & 1.99 & 0.88 & 33.01 & 29.20 & 1.26 & 3.81 & 1.99 & 0.88 \\
\hline Kawimera & 39.10 & 32.60 & 1.67 & 6.50 & 2.65 & 0.83 & 39.10 & 32.60 & 1.67 & 6.50 & 2.65 & 0.83 \\
\hline
\end{tabular}

${ }^{a}$ RYp, root under optimum irrigation; RYs, root under deficit irrigation; STI, stress tolerance index; TOL, stress tolerance; SSI, stress susceptibility index; YSI, yield stability index; SYp, sugar under optimum irrigation; Sys, sugar under deficit irrigation.

tolerance (TOL) value, the greater the reduction in root and sugar yields (RY and SY, respectively) under stress conditions, and the higher the sensitivity of a genotype to deficit irrigation (Table 4). Pearson correlation analysis between stress tolerance indexes and average values of genotypes root and sugar yields under deficit- irrigation (RYs and SYs) and optimum-irrigation (RYp and SYp) conditions exhibited significant correlations between TOL and stress susceptibility index (SSI), and yield stability index (YSI) for RY and SY (Tables 5, 6). The positive significant correlations between TOL and optimum-irrigated yields (Yp) and the negative correlations between TOL and yields under deficit irrigation conditions (Ys; Tables 5, 6) suggest that using TOL as a selection index will result in yield reduction under optimum-irrigated conditions. The results revealed that there was a positive significant correlation among Yp and stress tolerance index (STI), and Ys and STI for root sugar yields, suggesting that STI is a better predictor of Yp and Ys than TOL, SSI, and YSI. The general linear model regression of root and sugar yields under deficit irrigation conditions on STI revealed a positive correlation between these criteria with a similar coefficient of determination $\left(R^{2}=.97\right.$ and .98 , respectively; Figure 2).

\section{4 | DISCUSSION}

The present study was carried out to evaluate the performance and yielding ability of sugar beet genotypes for irrigation deficiency under heat stress conditions in Upper Egypt. In the light of steady population growth, diminishing sugarcane cultivated area, and irrigation shortage, increasing sugar beet cultivated area is the only possible solution to overcome the gap between sugar production and consumption in Egypt (Abou-Elwafa, 2011). This necessitates the establishment of a national sugar beet breeding program to select for high yielding genotypes that are tolerant to deficit irrigation and high temperatures. Furthermore, drought stress is frequently 
TA B L E 5 Pearson correlation coefficient (R) between drought stress indices and average root yield over the two growing seasons

\begin{tabular}{lllllll} 
& & RYp $^{\mathrm{a}}$ & RYs & STI & TOL & SSI \\
\hline Season 2 & RYs & $.897^{* *}$ & & & & \\
Season 3 & & $.977^{* *}$ & & & & \\
\hline Season 2 & STI & $.953^{* *}$ & $.968^{* *}$ & & & \\
Season 3 & & $.996^{* *}$ & $.990^{* *}$ & & & \\
\hline Season 2 & TOL & $.659^{*}$ & -.234 & $.436^{*}$ & & \\
Season 3 & & $.531^{*}$ & -.014 & $.460^{*}$ & & \\
Season 2 & SSI & .213 & .259 & -.035 & $.865^{* *}$ & \\
\hline Season 3 & & .225 & .337 & .140 & $.930^{* *}$ & \\
\hline Season 2 & YSI & -.217 & .230 & .030 & $-.865^{* *}$ & $-.999^{* *}$ \\
Season 3 & & -.187 & .023 & -.101 & $-.913^{* *}$ & $-.998^{* *}$ \\
\hline
\end{tabular}

*Significant at the .05 probability level;

${ }^{* *}$ Significant at the .01 probability level.

${ }^{a}$ RYp, root under optimum irrigation; RYs, root under deficit irrigation; STI, stress tolerance index; TOL, stress tolerance; SSI, stress susceptibility index; YSI, yield stability index.

TA B L E 6 Pearson correlation coefficient (R) between drought stress indices and average recoverable sugar yield over the two growing seasons

\begin{tabular}{llcllll} 
& & \multicolumn{1}{c}{ SYp } & Sys & STI & TOL & SSI \\
\hline Season 2 & SYs & $.924^{* *}$ & & & & \\
Season 3 & & $.970^{* *}$ & & & & \\
\hline Season 2 & STI & $.965^{* *}$ & $.975^{* *}$ & & & \\
\hline Season 3 & & $.995^{* *}$ & $.987^{* *}$ & & & \\
\hline Season 2 & TOL & $.629^{*}$ & -.284 & $.438^{* *}$ & & \\
\hline Season 3 & & $.457^{*}$ & -.285 & -.345 & & \\
\hline Season 2 & SSI & .132 & -.254 & -.089 & $.845^{* *}$ & \\
\hline Season 3 & & -.294 & -.516 & -.382 & $.992^{* *}$ & \\
\hline Season 2 & YSI & -.152 & .234 & .068 & $-.855^{* *}$ & $-.999^{* *}$ \\
Season 3 & & .295 & .517 & .382 & $-.992^{* *}$ & $-.999^{* *}$ \\
\hline
\end{tabular}

*Significant at the .05 probability level;

${ }^{* *}$ Significant at the .01 probability level.

${ }^{a}$ SYp, sugar under optimum irrigation; Sys, sugar under deficit irrigation; STI, stress tolerance index; TOL, stress tolerance; SSI, stress susceptibility index; YSI, yield stability index.

associated with heat stress in field conditions, which makes the development of sugar beet lines responding to combined drought and heat stress necessary.

In that context, a panel of 18 sugar beet breeding lines produced at the USDA-ARS-NWISRL, in Kimberly, ID, in addition to the commercial sugar beet cultivar Kawimera, one of the most widely cultivated sugar beet cultivars in Upper Egypt, were preliminarily evaluated for performance and yielding ability under high temperature conditions in the first growing season. Out of those 18 breeding lines, six lines exhibited superiority in yield and quality traits under high temperatures in addition to the promising line USKPS25 and the commercial cultivar
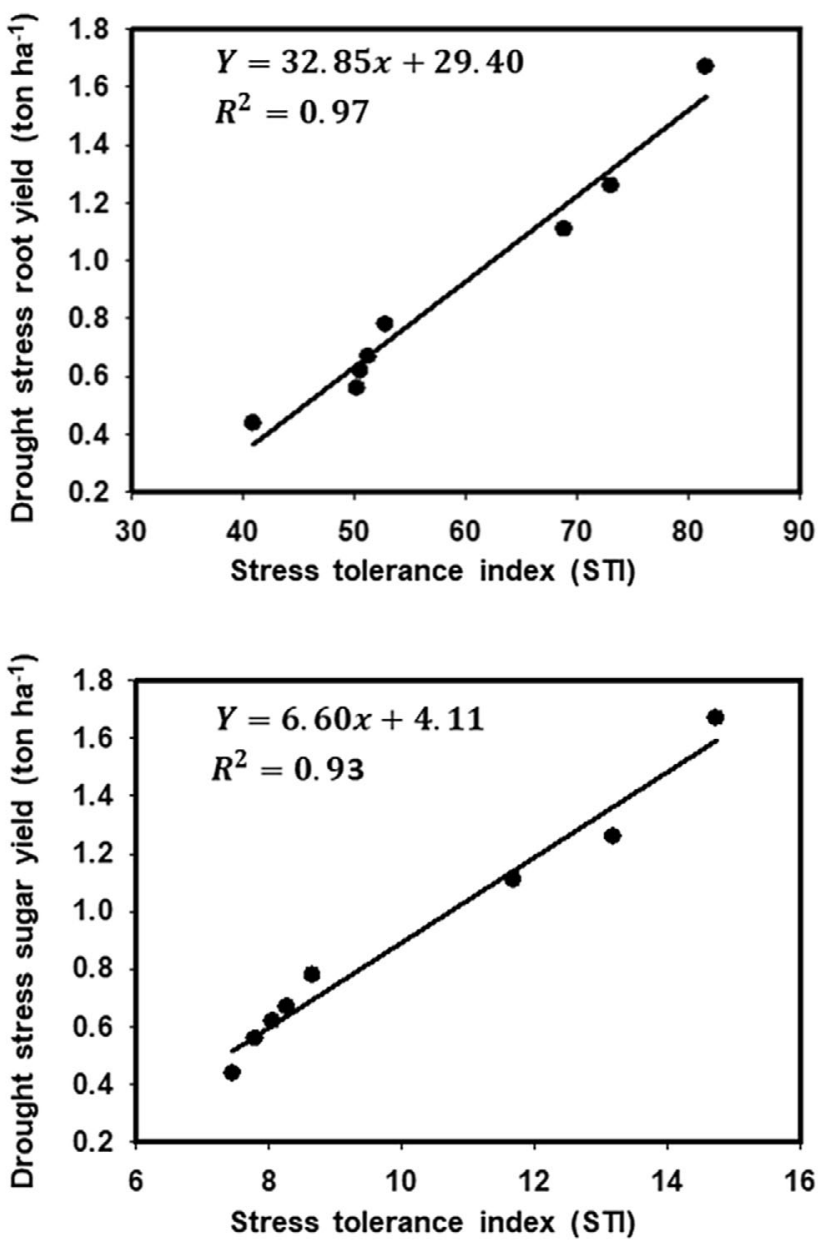

F I G U R E 2 Relationship between deficit irrigation average root and sugar yields (ton $\mathrm{ha}^{-1}$ ) and stress tolerance index (STI)

Kawimera which were evaluated for irrigation deficiency for two successive growing seasons. The irrigation deficiency treatment was irrigated when the soil moisture reached about $26 \%$ of the soil field capacity, which was equivalent to $65 \%$ of the field capacity at optimum irrigation (40\%).

Evaluated traits reacted differently to deficit irrigation, signifying the adverse effect of deficit irrigation stress on sugar beet. All evaluated genotypes performed differently under deficit irrigation stress conditions indicating genetic variability in the sugar beet panel of breeding lines with respect to drought stress tolerance. The high yield performance of all evaluated genotypes observed in the third growing season under both optimum- and deficit-irrigation conditions could be in due to (a) sowing at high planting density in that growing season compared to the two previous seasons ( 10 vs. $15-$ to $20-\mathrm{cm}$ spaces between plants), and (b) the enhanced accumulation of dry matter in roots caused by increasing temperature and high solar radiation during this growing season (Figure 3; Kenter, Hoffmann, \& Märländer, 2006). The 


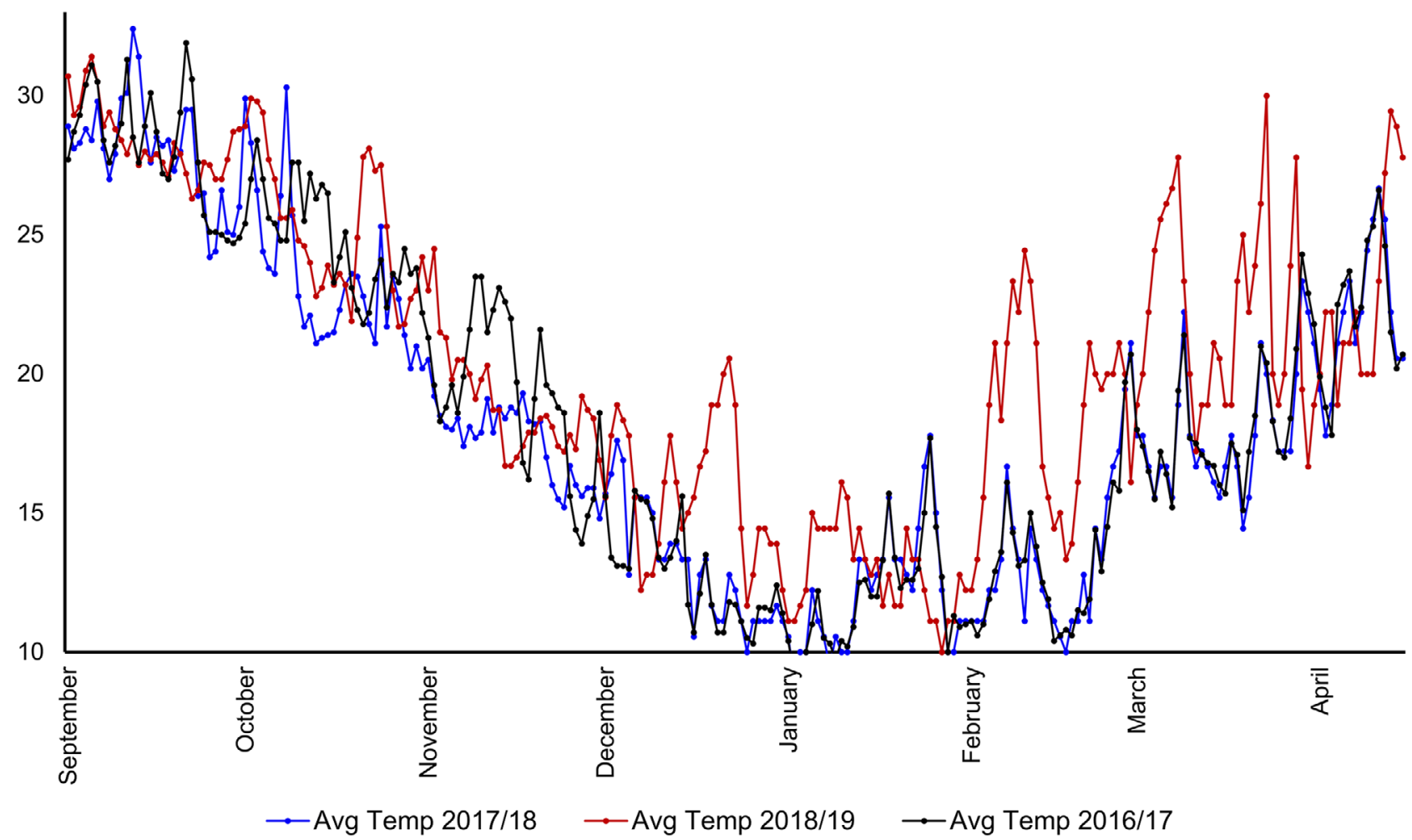

F I G U R E 3 Average day and night temperatures in the field from 1 September to 15 April during the 2016-2017, 2017-2018, and 2018-2019 growing seasons

results show considerable genetic variations in quality traits; however, the effect of environmental conditions is obvious especially for $\mathrm{Na}, \mathrm{K}$, and $\alpha$-amino- $\mathrm{N}$ contents, which have been reported (Bosemark, 1993). Unlike the significant reductions in $\alpha$-amino- $\mathrm{N}$ content, deficit irrigation has only small, inconsistent effects on $\mathrm{Na}$ and $\mathrm{K}$ concentrations. This is probably due to the various counteracting effects of deficit irrigation on ion uptake (Last, Draycott, Messem, \& Webb, 2009; Winter, 1990).

Four drought stress indices-TOL, STI, SSI, and YSIwere used to identify high yielding genotypes under stressed and non-stressed environments. Since correlations between stress tolerance indices for all studied traits are similar, only the correlations for root and recoverable sugar yields were presented and discussed. The STI was the only stress index that has positive correlations with average root and recoverable sugar yields under both optimum irrigated and deficit irrigation conditions. The significant positive correlations found between STI, and average yields under stressed conditions (Ys) and average yields under non-stressed conditions (Yp) in the two growing seasons indicate that STI is the best stress index that can be used to predict for average productivity compared to other stress indices (SSI, TOL, and YSI). Therefore, the selection of genotypes of high yielding performance based on SSI, TOL, or YSI stress indices may not result in vari- eties that are productive in unlike environments. Besides, the linear relationship between STI and average root and recoverable sugar yields (Figure 2), indicating that STI could be implemented in identifying high yielding genotypes under both optimum irrigated and deficit irrigation conditions. However, when other stress indices (TOL, SSI, and YSI) were plotted against average sugar yield (Supplemental Figure 1), no linear relationship was observed in all cases, implying that neither TOL, nor SSI and YSI could be implemented to identify high yielding droughttolerant genotypes under unlike environments. Similar results were obtained by Fernandez (1992) in mung bean (Vigna radiata), in sugar beet by Sadeghian, Fazl, Mohammadian, Taleghani, and Mesbah (2000), and in wheat by Talebi, Fayaz, and Naji (2009).

Deficit-irrigation-tolerance breeding program should focus on the selection of genotypes with high root and sugar yield in unlike environments. Therefore, because of their high yield performance under optimum-irrigated and drought-stressed conditions and their high STI values, USKPS25 and USC944-6-68 breeding lines (scored the highest root and sugar yields after the commercial cultivar) seem to be more adapted to deficit irrigation and high temperature conditions. This emphasizes the advantage of implementing STI as a criterion to select high yielding performance and stress-tolerant genotypes. Therefore, 
it is intended to implement these particular breeding lines USKPS25 and USC944-6-68 in any sugar beet breeding or crossing activities.

In conclusion, a preliminary evaluation of 18 sugar beet breeding lines produced at the USDA-ARS-NWISRL in Kimberly, ID identified six high yielding lines under high temperature conditions. Evaluation of those six lines in addition to a promising breeding line for deficit-irrigation stress tolerance revealed the superiority of two lines, that is, USKPS25 and USC944-6-68, in yield and quality under optimum- and deficit-irrigation conditions. Besides, the two lines exhibited high STI values, thus seem to be better adapted to deficit irrigation and high temperature conditions and should therefore be implemented in any sugar beet breeding programs.

\section{ACKNOWLEDGMENTS}

The research work is funded by the Beet Sugar Development Foundation (BSDF) Project No. 321. The authors thank the staff of the Agronomy Department Farm at Assiut University for technical assistance. The authors gratefully acknowledge Mr. Hatim I. Eujayl for critical revision of the manuscript.

\section{CONFLICTS OF INTEREST}

The authors report no conflicts of interest.

\section{O R C ID}

\section{Salah F. Abou-Elwafa (1) https://orcid.org/0000-0002-}

9018-598X

\section{REF E R E N C ES}

Abdelgader, H., Eltahir, S. A. M., Abbas, B., \& Abdelrahim, A. (2013). Efforts to Introduce Sugar Beet Crop in Sudan for a Sustainable Improvement of Agricultural Production in Rural Communities, Tropentag: Agricultural development within the rural-urban continuum, Stuttgart-Hohenheim, Germany, September 17-19, 2013.

Abo-Elwafa, S. F., Abdel-Rahim, H. M., Abou-Salama, A. M., \& Teama, E. A. (2006). Sugar beet floral induction and fertility: Effect of vernalization and day-length extension. Sugar Tech, 8, 281-287. https://doi.org/10.1007/BF02943569

Abou-Elwafa, S. F. (2011). Novel Genetic Factors Affecting Bolting and Floral Transition Control in Beta vulgaris (Doctoral dissertation). Christian Albrechts University of Kiel, Germany.

Abou-Elwafa, S. F., \& Shehzad, T. (2018). Genetic identification and expression profiling of drought responsive genes in sorghum. Environmental and Experimental Botany, 155, 12-20. https://doi. org/10.1016/j.envexpbot.2018.06.019

Ali, M. H. (2010). Fundamentals of irrigation and on-farm irrigation management (Vol. 1). New York, NY: Springer Science + Business Media.

Balakrishnan, A., \& Selvakumar, T. (2009). Evaluation of suitable tropical sugar beet hybrids with optimum time of sowing. Sugar Tech, 11, 65-68. https://doi.org/10.1007/s12355-009-0011-y
Bosemark, N. O. (1993). Genetics and breeding. In D. A. Cooke \& R. K. Scott (Eds.), The Sugar beet Crop (pp. 67-119). London, UK: Chapman and Hall.

Bouslama, M., \& Schapaugh, W. T. (1984). Stress tolerance in soybeans. I. evaluation of three screening techniques for heat and drought tolerance1. Crop Science, 24, 933-937. https://doi.org/10. 2135/cropsci1984.0011183X002400050026x

Kenter, C., Hoffmann, C. M., \& Märländer, B. (2006). Effects of weather variables on sugar beet yield development (Beta vulgaris L.). European Journal of Agronomy, 24(1), 62-69. https://doi.org/ 10.1016/j.eja.2005.05.001

Fernandez, G. C. J. (1992). Effective selection criteria for assessing stress tolerance. In C. G. Kuo (Ed.), Proceedings of the International Symposium on Adaptation of Vegetables and Other Food Crops in Temperature and Irrigation Stress (pp. 257-270). Tainan, Taiwan: Academia Sinica, Institute of Botany.

Fischer, R. A., \& Maurer, R. (1978). Drought resistance in spring wheat cultivars. I., Grain yield response. Australian Journal of Agricultural Research, 29(5), 897-912. https://doi.org/10.1071/ AR9780897

Hossain, A. B. S., Sears, R. G., Cox, T. S., \& Paulsen, G. M. (1990). Desiccation tolerance and its relationship to assimilate partitioning in winter wheat. Crop Science, 30, 622-627. https://doi.org/10. 2135/cropsci1990.0011183X003000030030x

IPCC. (2007). Climate change 2007: Impacts, adaptation and vulnerability. In Parry M. L., Canziani O. F., Palutikof J. P., Linden P. J. v. d., \& Hanson C. E., (Eds.), Contribution of Working Group II to the Fourth Assessment Report of the Intergovernmental Panel on Climate Change (pp. 211-273). Cambridge, UK: Cambridge University Press.

Last, P. J., Draycott, A. P., Messem, A. B., \& Webb, D. J. (2009). Effects of nitrogen fertilizer and irrigation on sugar beet at Broom's Barn 1973-8. The Journal of Agricultural Science, 101, 185-205. https:// doi.org/10.1017/S0021859600036509

Mandere, M. N., Persson, A., Anderberg, S., \& Pilesjo, P. (2010). Tropical sugar beet land evaluation scheme: Development, validation and application under Kenyan condition. GeoJournal, 75, 215-228. https://doi.org/10.1007/s10708-009-9302-9

Mawusi, S. E. (2004). Farmers' Knowledge and Perception towards a Sustainable Adoption of Sugar Beet in Kenya (Master's thesis). Lund, Sweden: Lund University.

Mohammad, A. E. H., Ahmed, A. O., \& Marchelo-d'Ragga, P. W. (2015). Evaluation of Sowing date and Harvesting Ages of Some Sugar Beet (Beta vulgaris subsp. vulgaris) Cultivars under Guneid conditions, (Sudan). International Journal of Agricultural Research and Review, 3(9), 421-424.

Moosavi, S. G. R., Ramazani, S. H. R., Hemayati, S. S., \& Gholizade, H. (2017). Effect of drought stress on root yield and some morphophysiological traits in different genotypes of sugar beet (Beta vulgaris L.). Journal of Crop Science and Biotechnology, 20, 167-174. https://doi.org/10.1007/s12892-017-0009-0

Nasr, M. I., \& Abd El-Razek, A. M. (2008). Sugar beet performance under newly reclaimed soils conditions of Sinai, Egypt. Sugar Tech, 10, 210-218. https://doi.org/10.1007/s12355-008-0039-4

Ober, E. S., Bloa, M. L., Clark, C. J. A., Royal, A., Jaggard, K. W., \& Pidgeon, J. D. (2005). Evaluation of physiological traits as indirect selection criteria for drought tolerance in sugar beet. Field Crops Research, 91, 231-249. https://doi.org/10.1016/j.fcr.2004. 07.012 
Ober, E. S., \& Luterbacher, M. C. (2002). Genotypic variation for drought tolerance in Beta vulgaris. Annals of Botany, 89, 917-924. https://doi.org/10.1093/aob/mcf093

Putnik-Delić, M., Maksimović, I., Nagl, N., \& Lalić, B. (2018). Sugar beet tolerance to drought: Physiological and molecular aspects. In V. Andjelkovic (Ed.), Plant, Abiotic Stress and Responses to Climate Change (pp. 389-402). London, UK: InTechOpen.

Reinefield, E., Merich, A. E. M., Baumgarten, G., Winner, C., \& Besis, U. (1974). Zur voraussage des melassezyu cherus aus ru beanalysen. In D. A. Cooke \& R. K. Scott (Eds.), The Sugar beet Crop (pp. 571-617). London, UK: Chapman and Hall.

Sadeghian, S. Y., Fazl, H., Mohammadian, R., Taleghani, D. F., \& Mesbah, M. (2000). Genetic variation for drought stress in sugarbeet. Journal of Sugar Beet Research, 37, 55-77. https://doi.org/10.5274/ jsbr.37.3.55

Sen, A., \& Alikamanoglu, S. (2012). Analysis of drought-tolerant sugar beet (Beta vulgaris L.) mutants induced with gamma radiation using SDS-PAGE and ISSR markers. Mutation Research/Fundamental and Molecular Mechanisms of Mutagenesis, 738-739, 38-44. https://doi.org/10.1016/j.mrfmmm.2012. 08.003

Shaw, B., Thomas, T. H., \& Cooke, D. T. (2002). Responses of sugar beet (Beta vulgaris L.) to drought and nutrient deficiency stress. Plant Growth Regulation, 37, 77-83. https://doi.org/10.1023/ A:1020381513976

Singh, S., Sidana, B. K., \& Kummar, S. (2018). Water productivity of sugarbeet vs sugarcane cultivation in Punjab. International Journal for Innovative Research in Science \& Technology, 4, 61-69.
Simova-Stoilova, L., Vassileva, V., \& Feller, U. (2016). Selection and breeding of suitable crop genotypes for drought and heat periods in a changing climate: Which morphological and physiological properties should be considered? Agriculture, 6(2), 1-19. https://doi.org/10.3390/agriculture6020026

Talebi, R., Fayaz, F., \& Naji, A. M. (2009). Effective selection criteria for assessing drought stress tolerance in durum wheat (Triticum durum Desf.). General and Applied Plant Physiology, 35(1-2), 64-74.

Winter, S. R. (1990). Sugarbeet response to nitrogen as affected by seasonal irrigation. Agronomy Journal, 82, 984-988. https://doi.org/ 10.2134/agronj1990.00021962008200050029x

\section{SUPPORTING INFORMATION}

Additional supporting information may be found online in the Supporting Information section at the end of the article.

How to cite this article: Abou-Elwafa SF, Amin AEA, Eujayl I. Genetic diversity of sugar beet under heat stress and deficit irrigation. Agronomy Journal. 2020;112:3579-3590.

https://doi.org/10.1002/agj2.20356 